\title{
Side Weir Flow on a Movable Bed
}

\author{
Giovanni Michelazzo ; Lorenzo Minatti²; Enio Paris ${ }^{3}$; and Luca Solari ${ }^{4}$
}

\begin{abstract}
Side weirs are hydraulic structures widely used for flow control in rivers and canals. Whenever the water level rises above the side weir crest elevation, a fraction of the main flow is diverted so that the water discharge flowing downstream in the main channel is reduced. In movable bed channels, the lateral outflow may have significant interactions with the sediment transport processes affecting the side weir flow. The spilled discharge creates a reduction of the downstream sediment transport capacity with a consequent deposition in the side weir proximity. In addition, sediment in the main channel can be diverted into the lateral branch. To investigate these interactions, experimental data at the laboratory scale have been collected and analyzed. The increase of the spilled discharge induced by the local sediment deposition is described according to the classical De Marchi hypothesis. Furthermore, the sediment transport leaving the main channel through the lateral structure is modeled in terms of the stream power associated with the bed-shear stress. Results allow for prediction of the bed dynamics and for the development of new design criteria. DOI: 10.1061/(ASCE)HY.1943-7900.0001128. (C) 2016 American Society of Civil Engineers.
\end{abstract}

Author keywords: De Marchi hypothesis; Movable bed; Sediment transport; Side weir; Spilled discharge.

\section{Introduction}

Side weirs are hydraulic control structures used to divert flow from the main channel into a branch channel. When used for flood protection, a fraction of the flood discharge is diverted into temporary lateral storage or into a diversion channel. Side weirs are designed so that the spilling starts as the water level reaches the crest level. In rivers, this condition can be affected by seasonal and long-term changes associated with several factors, including the growth of vegetation and bed sediment deposition or erosion. For instance, if sediment deposition occurs in front of the weir, water is diverted at different stages as compared with the undisturbed bottom condition, thereby modifying the design efficiency of the floodstorage area.

From a hydrodynamic point of view, the flow field of side weirs becomes complex with the growth of three-dimensional (3D) vortices induced by the streamline curvature of the diverted flow (Montes 1998). The weir is drawing water mainly from the surface layers at the upstream end, while the discharge tends to be drawn from the lower layers further downstream where the streamlines follow a spiral pattern (Neary et al. 1999). The flow along the opposite channel side is affected by the lateral outflow to a lesser extent and continues within the main channel (May et al. 2003). As the discharge in the main channel decreases along the weir, the flow

\footnotetext{
${ }^{1}$ Postdoctoral Researcher, Dept. of Civil and Environmental Engineering, Univ. of Florence, via di Santa Marta 3, 50139 Firenze, Italy. E-mail: giovanni.michelazzo@dicea.unifi.it

${ }^{2}$ Postdoctoral Researcher, Dept. of Civil and Environmental Engineering, Univ. of Florence, via di Santa Marta 3, 50139 Firenze, Italy (corresponding author). E-mail: lminatti@ dicea.unifi.it

${ }^{3}$ Professor, Dept. of Civil and Environmental Engineering, Univ. of Florence, via di Santa Marta 3, 50139 Firenze, Italy. E-mail: eparis@ dicea.unifi.it

${ }^{4}$ Associate Professor, Dept. of Civil and Environmental Engineering, Univ. of Florence, via di Santa Marta 3, 50139 Firenze, Italy. E-mail: luca.solari@unifi.it

Note. This manuscript was submitted on May 12, 2014; approved on November 5, 2015; published online on February 25, 2016. Discussion period open until July 25, 2016; separate discussions must be submitted for individual papers. This paper is part of the Journal of Hydraulic Engineering, (C) ASCE, ISSN 0733-9429.
}

depth varies in a way that depends on the flow regime. In a fixedbed prismatic channel, the flow depth increases along the weir length for subcritical flows, while it decreases for supercritical flows.

The complexity of the flow field is higher at larger spilled flow rates; since it depends also on the hydraulic head over the weir crest, the lower the crest elevation, the greater the flow rate over the side weir. As a consequence, in the limiting case of zero-height crests, i.e., as the crest elevation approaches the bed elevation, the flow field becomes highly $3 \mathrm{D}$ and the hydrodynamic conditions are similar to lateral intake flows. Contributions on these 3D issues are given by Hager and Volkart (1986) and Michelazzo et al. (2015) for side weirs with zero crest height, and by Neary et al. (1999) and Hsu et al. (2002) for lateral intakes.

Side weirs have been mostly studied in fixed-bed conditions, i.e., without considering sediment-transport and bed-mobility processes. These contributions concern the analytical prediction of a change of flow depth along the weir by considering a constant discharge coefficient (e.g., Borghei et al. 1999; Muslu 2001). Other contributions focus on the evaluation of the discharge coefficient $\mu$ as a function of the geometrical and flow properties of the main channel and the side weir in order to estimate the outflow properties (Borghei et al. 1999; Hager 1987; Muslu 2001).

In natural rivers, sediment transport and bed mobility may become important factors affecting the performance of a side weir. Significant morphological changes are expected to occur in a short bed reach along the weir location, due to both the local reduction of sediment transport capacity in the main channel and the strong vorticity of the flow field. Few studies regarding the interaction between a movable bed and a side weir flow are available. Rosier et al. (2005) performed experimental investigations to analyze the interaction between the side weir and the main channel flows in a sand-bed river. Catella et al. (2007) analyzed the effects of bed mobility on side weir efficiency by using a river morphodynamic model. The experiments of Paris et al. (2012) using a laboratory flume with movable bed in subcritical flow conditions suggested that side weirs may affect bed morphology. These data showed bed deformation as a positive step in the reach facing the weir due to (1) sediment deposition at the downstream end of the weir induced by the reduction of discharge in the main channel, and (2) erosion at the upstream end of the weir driven by flow acceleration. The step 
appeared to influence the performance of the weir, so that the percentage of spilled discharge increased with its height. Paris et al. (2012) verified the applicability of the De Marchi hypothesis (i.e., constant total head along the weir) for a movable bed based on their experimental data in subcritical flow conditions. These are here extended and analyzed to describe two features related to the interactions between bed mobility and lateral flow: (1) the increase of the spilled water discharge induced by bed deformations in the proximity of the side weir, and (2) the estimate of sediment transport leaving the main channel over the side weir sill.

The phenomenon concerning the increase of spilled water discharge has also been observed by Rosier et al. (2005), who found that the spilled discharge in a movable bed may increase up to $40 \%$ with respect to that obtained with the same conditions before the bed started to adjust to the flow by changing its profile. However, the sediment transport passing over the side weir appears to have never been investigated, notwithstanding its implications on the side weir's performance and the main channel's morphodynamics.

The goals of the present study are (1) to investigate the effects on side weir efficiency induced by local bed deformation, and (2) to evaluate the sediment transport passing over the weir. To this aim, a theoretical scheme is first developed and then compared with experimental data.

\section{Theoretical Framework}

A simplified theoretical framework is here developed to outline the physical variables primarily affecting the interaction between bed mobility and the performance of side weirs in prismatic channels in terms of effects of mobility on the spilled discharge and sediment transport over the side weir.

The main hypothesis at the base of the work is the validity of the De Marchi hypothesis in movable bed conditions, which was verified by Paris et al. (2012) for Froude numbers (F) up to 0.65. This constitutes a limitation of the theoretical framework.

\section{Effects of Bed Mobility on Spilled Discharge}

Following Paris et al. (2012), the De Marchi hypothesis preserves its validity even in movable bed conditions up to $F=0.65$ downstream of the side weir. Accordingly, the total head along the entire weir length is assumed to be constant

$$
z_{b 1}+h_{1}+\frac{Q_{u}^{2}}{2 g A_{1}^{2}}=z_{b 2}+h_{2}+\frac{\left(Q_{u}-Q_{s}\right)^{2}}{2 g A_{2}^{2}}
$$

where $Q_{u}$ and $Q_{s}=$ upstream and lateral spilled discharge, respectively; $z_{b}$ and $h=$ bed elevation and water depth, respectively; and $A=$ wetted cross-sectional area. Subscripts 1 and 2 refer to the upstream and downstream weir flow cross sections, respectively (Fig. 1). The Coriolis coefficients, which usually multiply the kinetic head term in Eq. (1), have been assumed to be equal to the unity.

The difference in the mean bed elevation between Cross Sections 1 and 2 is (Paris et al. 2012)

$$
z_{b 2}-z_{b 1}=k \cdot \Delta z
$$

where $\Delta z=$ bed deformation in front of the side weir as a consequence of the lateral spill; and $k<1=$ reduction coefficient to take into account the 3D bed deformation. Eq. (1) is rearranged in terms of discharge per unit width of the main channel, $q$, by expressing the rating curve as

$$
h=a \cdot q^{2 / 3}
$$

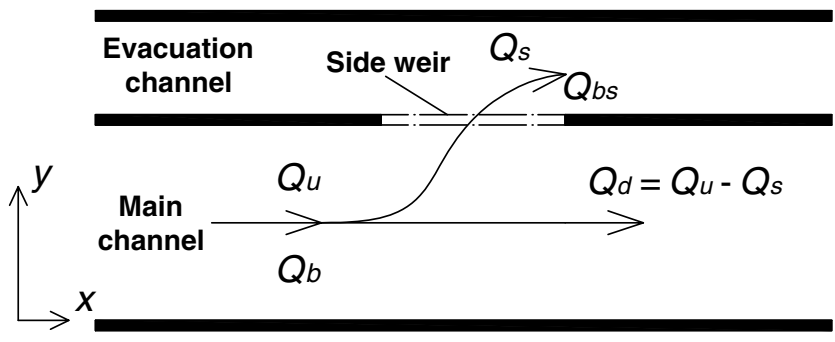

(a)

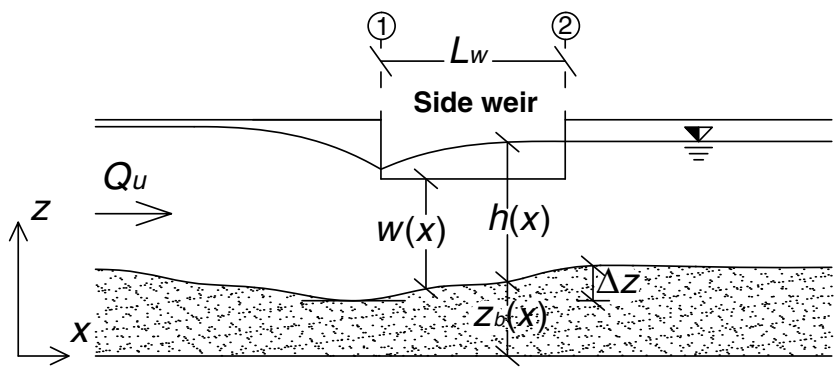

(b)

(c)

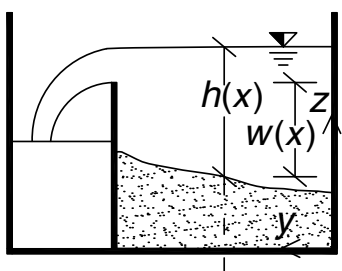

Centerline

Fig. 1. Sketch and notations: (a) plan view; (b) front view; (c) cross section ( $w$ and $h$ are measured at the main channel centerline)

where $a=$ dimensional coefficient, depending on the Froude number, $\mathrm{F}=q /(g \cdot h)^{1 / 2}$ as (Appendix)

$$
a=\frac{h}{q^{2 / 3}}=\frac{1}{g^{1 / 3} \mathrm{~F}^{2 / 3}}
$$

Considering a rectangular cross section of constant width $B$ and taking into account Eqs. (2) and (3), Eq. (1) becomes

$$
q_{u}^{2 / 3}\left(a_{1}+\frac{1}{2 g a_{1}^{2}}\right)=\left(q_{u}-q_{s}\right)^{2 / 3}\left(a_{2}+\frac{1}{2 g a_{2}^{2}}\right)+k \Delta z
$$

Finally,

$$
\frac{q_{s}}{q_{u}}=\frac{Q_{s}}{Q_{u}}=1-\left(\frac{f_{1}}{f_{2}}-\frac{k \Delta z}{q_{u}^{2 / 3} f_{2}}\right)^{3 / 2}=1-\left(\frac{f_{1}}{f_{2}}-\Delta z^{*}\right)^{3 / 2}
$$

where

$$
\begin{gathered}
f_{1}=a_{1}+\frac{1}{2 g a_{1}^{2}} ; \quad f_{2}=a_{2}+\frac{1}{2 g a_{2}^{2}} \\
\Delta z^{*}=\frac{k \Delta z}{q_{u}^{2 / 3} f_{2}}
\end{gathered}
$$

Eq. (6) provides a relationship between the ratio of spilled discharge $Q_{s}$ and the upstream discharge $Q_{u}$, and the main flow characteristics upstream and downstream of the weir, i.e., $f_{1}$ and $f_{2}$, and the dimensionless bottom step height $\Delta z^{*}$. 


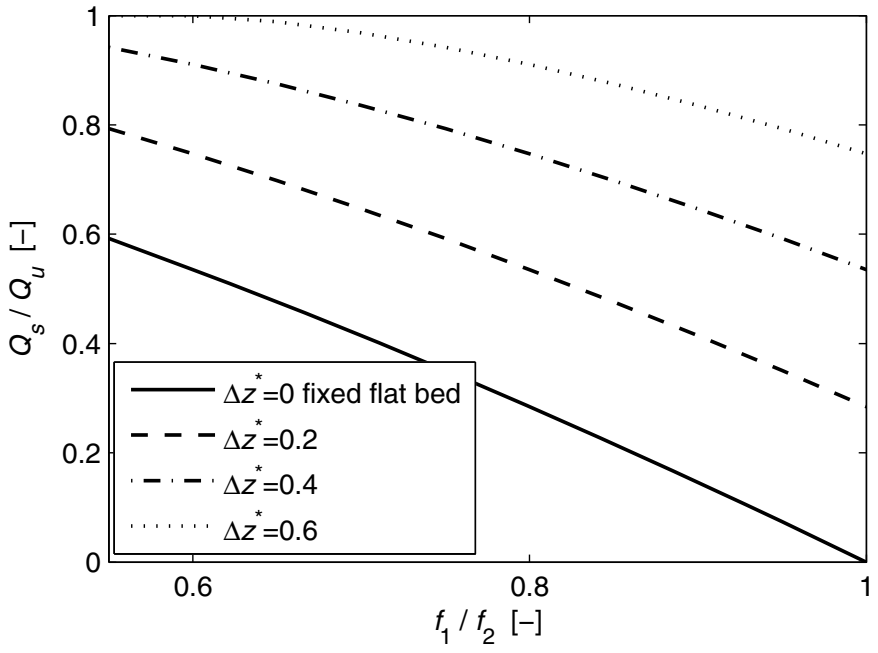

Fig. 2. $Q_{s} / Q_{u}$ ratio as a of function of $f_{1} / f_{2}$ for different values of dimensionless bottom step height $\Delta z^{*}$, according to Eq. (6)

Assuming subcritical flows with Froude numbers ranging between 0.2 and 0.8 , Eq. (4) provides values of $a$ in the interval 1.4-0.5. Eq. (6) has a physical meaning only if $0<Q_{s} / Q_{u}<1$ that is if $0<\left[\left(f_{1} / f_{2}\right)-\Delta z^{*}\right]^{3 / 2}<1$.

Hence, for the two terms in the brackets, the relation $\Delta z^{*}<$ $f_{1} / f_{2}<1+\Delta z^{*}$ must hold.

If $\Delta z^{*}=0$, the condition of a plane fixed bed occurs, for which the spilled discharge $Q_{s}$ entirely depends on the upstream and downstream main flow characteristics as

$$
\frac{q_{s}}{q_{u}}=\frac{Q_{s}}{Q_{u}}=1-\left(\frac{f_{1}}{f_{2}}\right)^{3 / 2}
$$

The ratio $Q_{s} / Q_{u}$ decreases as $f_{1} / f_{2}$ increases until, in the limiting case of $f_{1}=f_{2}$, no outflow takes place (i.e., unmodified hydraulic conditions upstream and downstream). If $\Delta z^{*}>0$, the ratio $Q_{s} / Q_{u}$ still decreases with increasing $f_{1} / f_{2} . Q_{s} / Q_{u}$ is larger for greater bed deformations, i.e., for increasing values of $\Delta z^{*}$; at constant $f_{1} / f_{2}$, this means that the bed deformation should enhance the water-outflow process.

The family of curves representing the variation of $Q_{s} / Q_{u}$ given by Eq. (9) for various values of $\Delta z^{*}$ is shown in Fig. 2. The ratio $Q_{s} / Q_{u}$ decreases to zero when considering the fixed flat-bed curve $\left(\Delta z^{*}=0\right)$ and $f_{1} / f_{2}=1$. The ratio $Q_{s} / Q_{u}$ also assumes values greater than zero when $f_{1} / f_{2}=1$ according to the movable-bed curves; this occurs because a bed modification $\Delta z^{*} \neq 0$ appears while flow conditions $\left(f_{1,2}\right)$ might still be the same at the upstream and downstream cross-sections.

\section{Sediment Transport Over the Side Weir}

During the spilling process, the flow field becomes complex with the growth of $3 \mathrm{D}$ eddies diverting sediment transport towards the weir. The estimation of the diverted sediment transport requires a detailed knowledge of both the flow field and the bed configuration near the weir location (Herrero et al. 2011). In the present work, a simplified, physics-based approach is proposed.

With reference to Fig. 1, let the total (bedload plus suspendedload) sediment discharge over the side weir, $Q_{b s}$ be

$$
Q_{b s}=\int_{0}^{L_{w}} q_{b s} d x
$$

where $L_{w}=$ weir crest length; and $q_{b s}=$ total diverted volumetric sediment discharge per unit length of the weir crest. According to Bagnold (1966), the available unit stream power is assumed to be the driving mechanism for sediment transport both as bedload and suspended load (Ali et al. 2012; Yang 1972). It appears reasonable to assume that, even for side weir flows, the flux of sediments over the weir is expressed as a function of the stream power associated with the spilled discharge. By denoting with $\tau_{x}, U_{x}, \tau_{y}$, and $U_{y}$ the bed-shear stress and the depth-averaged flow velocity along the main flow direction $x$ and the transverse direction $y$, respectively, the stream power per unit area of the diverted flow is $\tau_{y} \cdot U_{y}$. However, the efficiency of the transport process should depend on the turbulence intensity in the main channel and on its interaction with bed sediment. The sediment transport parameter $T$ of Van Rijn (1984) appears to be adequate to represent the efficiency coefficient as

$$
T=\frac{\tau-\tau_{c r}}{\tau_{c r}}
$$

where $\tau=\left(\tau_{x}^{2}+\tau_{y}^{2}\right)^{1 / 2}=$ total bed-shear stress; and $\tau_{c r}=$ critical value of bed-shear stress for the entrainment of particle motion. According to Bagnold (1966), the diverted volumetric sediment discharge per unit length $q_{b s}$ is expressed as

$$
q_{b s}=\frac{T \cdot \tau_{y} \cdot U_{y}}{\gamma_{s}}
$$

where $\gamma_{s}=$ specific weight of the solid material, here equal to $26 \mathrm{kN} / \mathrm{m}^{3}$. The quantities in Eqs. (11) and (12) are computed as

$$
\begin{gathered}
\tau_{y}(x)=\rho \frac{\sqrt{U_{x}(x)^{2}+U_{y}(x)^{2}}}{C(x)^{2}} U_{y}(x) \\
\tau_{x}(x)=\rho \frac{\sqrt{U_{x}(x)^{2}+U_{y}(x)^{2}}}{C(x)^{2}} U_{x}(x) \\
U_{y}(x)=\frac{1}{h(x)} \cdot \frac{d Q_{s}}{d x}(x) \\
U_{x}(x)=\frac{Q_{u}-Q_{s}(x)}{B \cdot h(x)}
\end{gathered}
$$

where $\rho=$ water density; and $C=$ nondimensional Chézy coefficient expressed in terms of skin friction as

$$
C(x)=7.66\left[\frac{h(x)}{2 D_{50}}\right]^{1 / 6}
$$

In Eq. (15), the cumulative spilled water discharge, $Q_{s}(x)$, at a distance $x$ from the upstream end of the side weir is evaluated according to the head-discharge relationship of a rectangular nonsubmerged weir as

$$
Q_{s}(x)=\int_{0}^{x} \mu \sqrt{2 g}[h(\eta)-w(\eta)]^{3 / 2} d \eta
$$

where $\mu=$ discharge coefficient, here assumed, for the sake of simplicity, constant and equal to $\mu=0.39$ for a sharp-crested weir (Nakayama and Boucher 1999).

The set of Eqs. (11)-(18), considering the flow depth profile $h(x)$ and the side weir height $w(x)$ with respect to the bed elevation to be known, can be solved with respect to the unknowns $\tau_{x}, \tau_{y}, T$, 
$q_{b s}, U_{x}, U_{y}, C$, and $Q_{s}$. This allows for the computation of sediment discharge through the side weir, $Q_{b s}$, from Eq. (10), once the weir length $L_{w}$, the bed sediment $D_{50}$, and the upstream discharge $Q_{u}$ are known.

\section{Laboratory Experiments}

The experiments were conducted in a prismatic rectangular $0.44-\mathrm{m}$ wide, 5-m-long, and 0.35-m-deep glass-sided water-recirculating feed flume (Fig. 1). It was subdivided into two separated channels by a vertical glass wall. The first one was the main channel, $0.30 \mathrm{~m}$ wide, representing the actual testing facility including the mobile bed [sand with median grain size $D_{50}=0.84 \mathrm{~mm}$ and geometric standard deviation $\left.\sigma_{g}=\left(D_{84} / D_{16}\right)^{1 / 2}=1.2\right]$ and the side weir on the left side. The second one, a 0.13-m-wide lateral channel, served for the spilled discharge to be evacuated. At about $2 \mathrm{~m}$ from the flume inlet, a rectangular window of adjustable size in both length and height was inserted on the vertical separation wall, which allowed for the lateral overflow.

Each experiment was composed of two sequential phases. During Phase 1, an initial bed morphology was allowed to self-adjust under the imposed liquid and sediment discharges while the lateral window was closed. Uniform flow conditions in the main channel were obtained by adjusting a vertical sluice gate at the downstream end. In all experiments, the main channel was operated under subcritical flow conditions, with $\mathrm{F}<0.5$ (for the undisturbed flow, at the beginning of Phase 1). The bedload discharge $Q_{b}$ fed from upstream was calibrated to be in equilibrium with the flow discharge and the bed slope in Phase 1. For those experiments carried out under entrainment conditions for sediment movement, $Q_{b}$ was set to zero.

Once equilibrium was reached (hereafter named Equilibrium Phase 1), Phase 2 started with the sudden opening of the lateral window. The side flow caused an acceleration of the flow towards the side weir and a consequent drawdown of the upstream zone. The flow acceleration induced mechanisms of bed degradation in the upstream reach of the main channel while the downstream decrease of discharge caused bed aggradation in front of the side weir. The test continued until a new equilibrium condition resulted (hereafter named Equilibrium Phase 2). In both phases, the equilibrium conditions were considered to be reached when consecutive measurements of the relevant physical parameters gave practically constant values.

Fig. 1 illustrates the relevant quantities measured during the experiments at Equilibrium Phases 1 and 2. The general layout of the experimental setup and measurement techniques are reported in Paris et al. (2012): the side overflow discharge was continuously determined by means of a calibrated sharp-crested weir located at the end of the evacuation channel. The total amount of sediment volume trapped inside the evacuation channel was measured at the end of each test; hence, an average value of the discharge $Q_{b s}$ was calculated with respect to the entire duration of Phase 2.

During the experiments, the $L_{w}$-flume width ratio ranged between 0.78 and 1.15 , the upstream water discharge $Q_{u}$ ranged between 6 and 12 l/s, the Froude number for the undisturbed flow (at the end of Phase 1) ranged between 0.29 and 0.50 , while the bedload sediment supply $Q_{b}$ reached up to $10^{-3} 1 / \mathrm{s}$.

\section{Experimental Observations}

The main channel bed assumed different configurations depending on the flow and sediment supply and on the equilibrium phase. In the experiments in which Phase 1 was characterized by a nonzero sediment transport, bedload was observed along the channel;
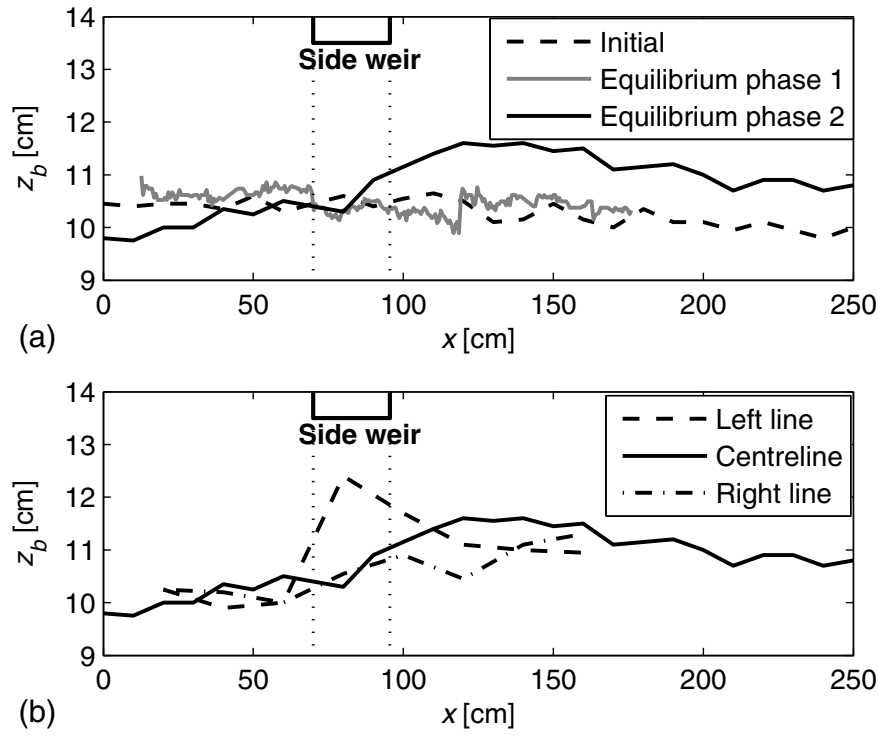

Fig. 3. Typical bed longitudinal profiles: (a) along the channel centerline at different experimental phases; (b) along different lines at Experimental Phase 2

sediment was fed at the channel entrance in such a way to reach Equilibrium Phase 1. No bed modifications occurred at the end of Phase 1 for runs without sediment supply and for which the flow conditions were below the threshold of sediment movement

Concerning Phase 2, experimental results indicate that the lateral outflow induces both a local bed deformation in front of the weir, and a generalized bed deformation in the reaches upstream and downstream of it. The sediment transport capacity of the main flow progressively reduces downstream along the side weir due to the spilled discharge with a consequent deposition. The accelerated free-surface profile triggered by the lateral outflow induces a general degradation in the reach upstream of the weir.

Along the weir, the bed morphology was characterized by the presence of a bed step particularly pronounced in the proximity of the side weir where a ramp-like deposit is generally formed, as observed by Rosier et al. (2005). All the tests were characterized by this similar behavior except for tests where no bedload was fed.

As an example, the surveyed longitudinal bed profiles of a typical test are reported in Fig. 3(a), regarding the comparison between centerline profile at initial and Equilibrium Phases 1 and 2, and in Fig. 3(b), regarding the comparison between bed profile at left, center and right lines at Equilibrium Phase 2. In particular, the left longitudinal profile (located at distance of one-sixth of the channel width from the side weir) features larger bed deformations in the form of a well-defined step.

The spilled discharge $Q_{s}$ was continuously monitored starting from the instant of side weir opening until reaching the equilibrium of Phase 2. Fig. 4 shows the temporal variation of $Q_{s}$ starting from the instant when the lateral window was opened $(t=0)$ for a typical test (a similar behaviour was observed in the other tests).

A first stage occurs in which discharge is rapidly increasing, followed by a much longer stage in which the discharge slowly increases towards the equilibrium value of Phase 2. The first transient stage is mainly attributed to the fast adjustment process of the water level and discharge induced by the sudden window opening, while the second is substantially related to the slower bed morphology change along the side weir alignment. Hence, the spilled discharge at the end of the first stage, $Q_{s}^{0}$, was assumed as the value of discharge spilled through the side weir when the bed is not yet 


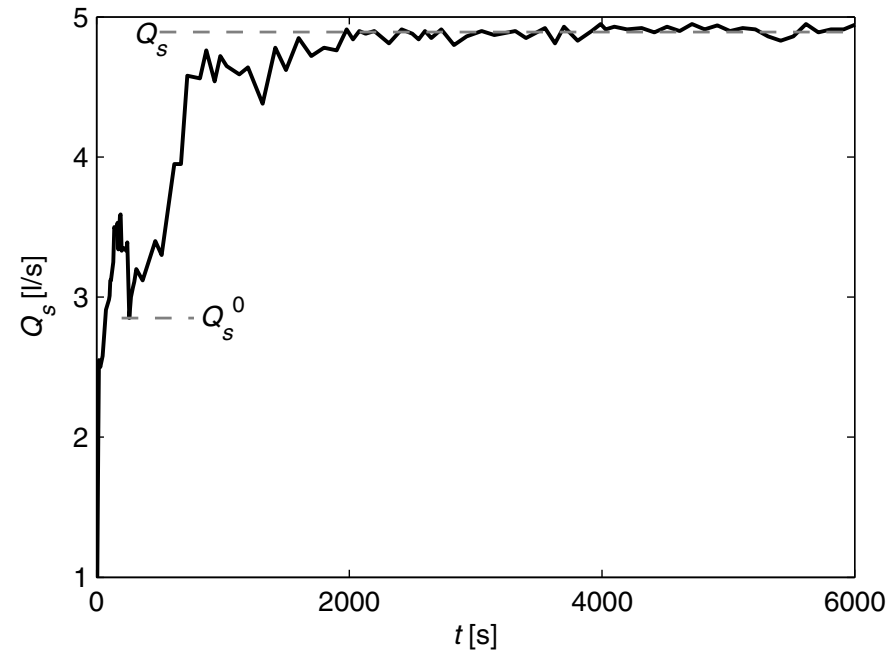

Fig. 4. Spilled discharge as a function of time for a typical test; $\left(Q_{s}^{0}\right.$ is spilled water discharge at the beginning of phase $2 ; Q_{s}$ is spilled discharge at the end of Phase 2)

significantly deformed by the side flow, while the final spilled discharge $Q_{s}$ at the end of Phase 2 is considered as the value for the deformed configuration of the bed. The spilled discharge increased up to about $50 \%$ because of the progressive bed deformation along the side weir alignment.

Sediment transport over the side weir, $Q_{b s}$, was observed in almost all runs. Typically, $Q_{b s}$ occurred in the form of both bedload and suspended load, while upstream and downstream of the side weir sediment was only transported as bedload. The increase of turbulence along the weir alignment, the local bed morphology, and the weir geometry were identified as the most relevant factors affecting this sediment transport.

\section{Results}

The results provided by the introduced theoretical framework are now compared with the experimental data.

\section{Effects of Bed Mobility on Spilled Discharge}

In Figs. 5 and 6, the $Q_{s} / Q_{u}$ ratio as predicted by Eq. (6) is compared with the experimental data. The theoretical predictions and the experimental data appear to be in agreement for every tested value of $\Delta z^{*}$. Fig. 5 indicates how almost all the experimental data lay above the fixed flat-bed curve $\left(\Delta z^{*}=0\right)$, indicating an effective increase in spilled discharge ratio.

Fig. 6 shows how almost all of the predictions lay within $\pm 20 \%$ with respect to the observed data. The theoretical framework also captures the laboratory data of Rosier (2007) obtained in experiments carried out in a much larger flume and longer weir.

Rosier et al. (2005) observed that in a movable bed, the overflow side discharge may increase up to $70 \%$ with respect to the condition of a flat bed due to the combined effects of the bed form's development and the local bed aggradation. Catella et al. $(2007,2008)$ used a numerical movable-bed model to simulate flow and bed morphodynamics of Rosier et al.'s (2006) experiments. A good agreement resulted between calculated and measured values for the spilled discharge. They both appear to be up to $80 \%$ larger than these obtained from undisturbed flat-bed flow simulations with the same boundary conditions.

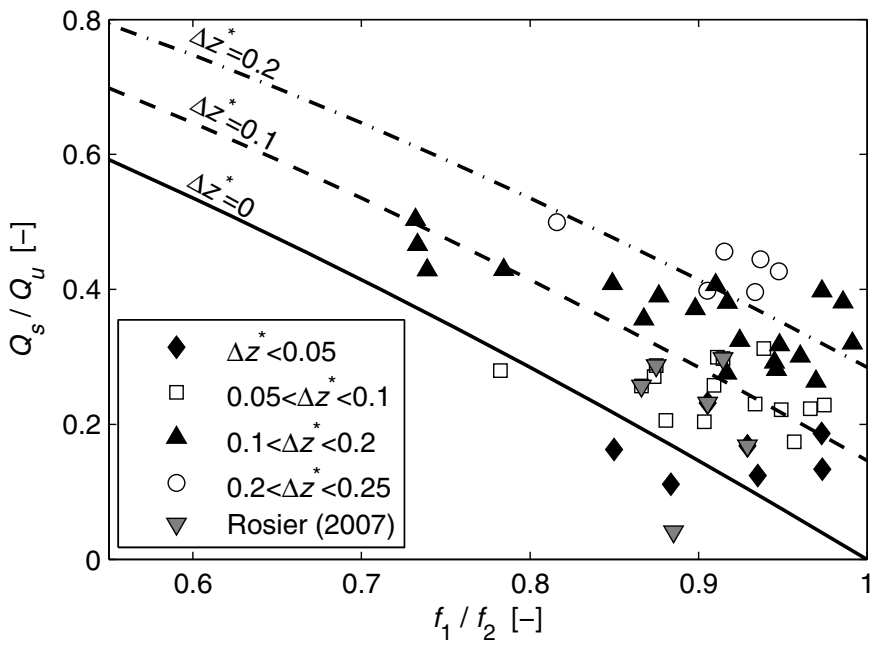

Fig. 5. Comparison between the theoretical and observed spilled discharge ratios as a function of $f_{1} / f_{2}$; experimental results from Rosier (2007) are also reported

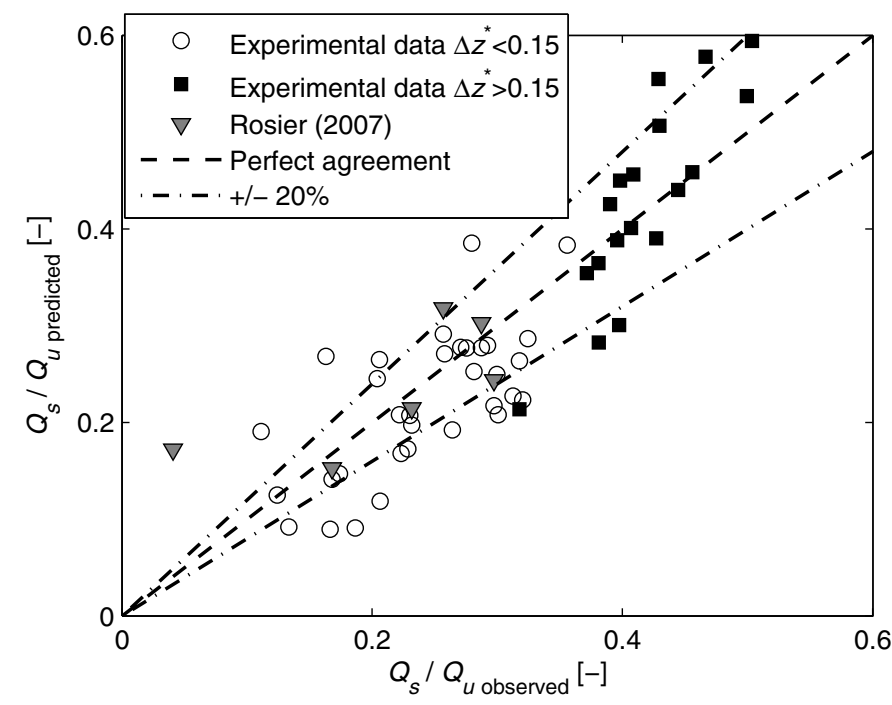

Fig. 6. Spilled discharge ratio for observed versus predicted data; dashed lines represent the $\pm 20 \%$ error interval with respect to the observed data; Rosier (2007) experiments are characterized by $\Delta z^{*}<0.1$

\section{Sediment Transport Over the Side Weir}

To solve Eqs. (11)-(18), it is necessary to know the profiles of $h(x)$ and $w(x)$ along the side weir. This was obtained via linear interpolation from the experimental data taken at its upstream and downstream ends. The integral in Eq. (10) was then evaluated to obtain the total sediment transport $Q_{b s}$. In Eq. (11) the critical shear stress $\tau_{c r}$ was derived by assuming a Shields parameter equal to 0.03 on the basis of a best data fit. Fig. 7 shows the nondimensional values of predicted and observed sediment transport in terms of average volume discharge per unit weir length as

$$
q_{b_{\text {predicted }}}^{*}=\frac{\frac{1}{L_{w}} \int_{0}^{L_{w}} q_{b s} d x}{\sqrt{g \cdot D_{50}^{3}}}
$$




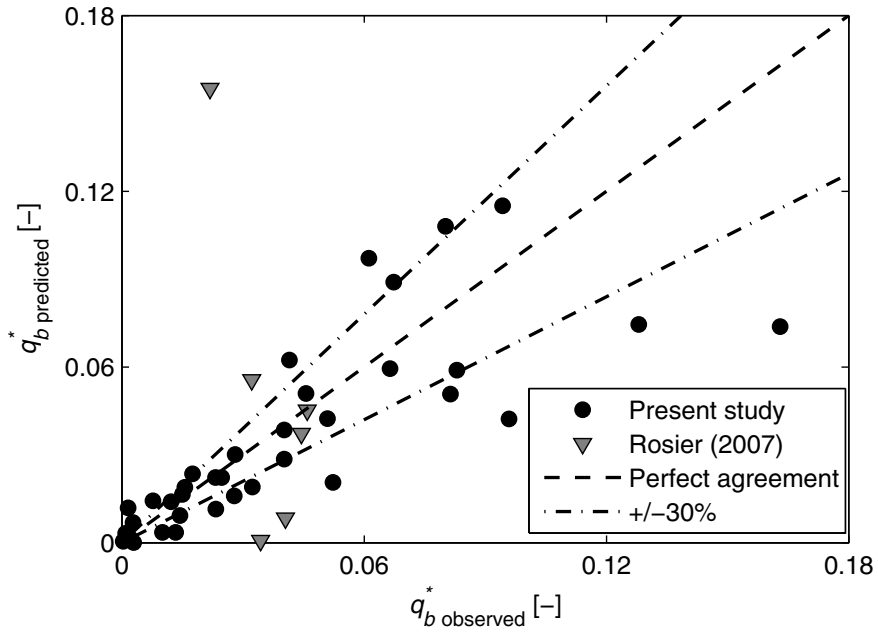

Fig. 7. Dimensionless diverted sediment transport per unit length: observed versus predicted data; dash-dot lines indicate $\pm 30 \%$ error interval with respect to observed data

$$
q_{b_{\text {observed }}}^{*}=\frac{\frac{Q_{b s}}{L_{w}}}{\sqrt{g \cdot D_{50}^{3}}}
$$

The plot shows a satisfactory agreement as $40 \%$ of the predicted data lay within the $\pm 30 \%$ error interval and $64 \%$ lay within $\pm 50 \%$. Considering the difficulties in obtaining accurate measurements of sediment transport and the large errors that usually affect its computation, this scatter appears reasonable.

Regarding the data of Rosier (2007), most of these are aligned with the overall trend of the present study. However, for the sediment load (Fig. 7), the prediction of the present model is less accurate than that regarding the water discharge (Fig. 6). Moreover, the diverted sediment transport was found to be of the same order of the input sediment transport. This finding suggests that side weir flow is efficient at diverting sediments from the main channel; however, this aspect needs to be further investigated with additional experiments.

\section{Conclusions}

Side weirs are traditionally designed and studied under fixed-bed conditions. A theoretical and experimental study to investigate the effect of a mobile bed on the side weir features was presented. The application of the De Marchi hypothesis for movable bed allows quantification of the effect of bed changes on the spilled discharge. Moreover, a physics-based framework to calculate the sediment transport diverted by the side weir is proposed. The proposed framework is based on some simplifying hypotheses that add to its readiness of use but also constitute a limitation of its applicability. The main simplifications are the validity of the De Marchi hypothesis in the case of a movable bed, which limits the maximum Froude number to 0.65 and the constancy of the side weir discharge coefficient. Furthermore, the bedload transport approach based on the theories of Van Rijn (1984) and Bagnold (1966), while being easily adaptable to the type of problem discussed in the present work, has some implicit limitations that should be taken into account in order to employ the proposed approach.

Laboratory experiments were performed for subcritical flow. Results indicate that side weir flow affects bed morphology by inducing, in the reach facing the weir, local erosion followed by a deposition, thereby generating a positive bed step. The analysis demonstrates that side weirs in movable beds are far more efficient at diverting the flow discharge than in the case of fixed beds. The experimental results indicate that the spilled discharge in movable beds increases up to $50 \%$ with respect to that occurring prior to substantial bed deformations. Also, a relevant process of sediment transport diversion through the side weir takes place during the spilling. The analysis of the experimental data shows a satisfactory agreement with the proposed model in terms of spilled discharge ratio and diverted sediment transport.

\section{Appendix. Derivation of Eqs. (3) and (4)}

For uniform flow in a rectangular channel with smooth walls and width $B$, a relationship between discharge and water depth $h$ is given by Chézy's law

$$
Q=B C \sqrt{g i_{b}} h^{3 / 2}
$$

where $i_{b}=$ bed slope; $C=$ nondimensional Chézy coefficient, here assumed to be constant; and the hydraulic radius is approximated by the water depth.

It is now possible to express the hydraulic depth in terms of discharge per unit width, $q=Q / B$, with the following:

$$
h=\left(\frac{q}{C \sqrt{g i_{b}}}\right)^{2 / 3}=a q^{2 / 3}
$$

where

$a=\left(\frac{1}{C \sqrt{g i_{b}}}\right)^{2 / 3}=\left(\frac{\sqrt{g h}}{\sqrt{g h} C \sqrt{g i_{b}}}\right)^{2 / 3}=\left(\frac{1}{\sqrt{g} \mathrm{~F}}\right)^{2 / 3}=\frac{1}{g^{1 / 3} \mathrm{~F}^{2 / 3}}$

\section{Notation}

The following symbols are used in this paper:

$A=$ wetted cross-sectional area of main channel $\left(\mathrm{m}^{2}\right)$;

$a_{1}=$ rating curve coefficient at entrance cross-sections of side weir $\left(\mathrm{s}^{2 / 3} \cdot \mathrm{m}^{-1 / 3}\right)$;

$a_{2}=$ rating curve coefficients at exit cross-section of side weir $\left(\mathrm{s}^{2 / 3} \cdot \mathrm{m}^{-1 / 3}\right)$

$B=$ main channel width $(\mathrm{m})$;

$C=$ dimensionless Chézy coefficient $(-)$;

$D_{x x}=$ sediment diameter for which $\mathrm{xx} \%$ of the sampled material (in weight) is finer ( $\mathrm{m})$;

$E_{1}=$ specific energy at entrance side weir cross-sections (m)

$E_{2}=$ specific energy at exit side weir cross-sections (m);

$\mathrm{F}=$ Froude number $(-)$;

$g=$ gravity acceleration $\left(\mathrm{m} / \mathrm{s}^{2}\right)$;

$h_{1}=$ approach flow depth at Equilibrium Phase $2(\mathrm{~m})$;

$h_{2}=$ downstream flow depth at Equilibrium Phase $2(\mathrm{~m})$;

$k=$ reduction coefficient $(-)$;

$L_{w}=$ side weir length (m);

$Q_{b}=$ bedload sediment supply $\left(\mathrm{m}^{3} / \mathrm{s}\right)$;

$Q_{b s}=$ total sediment discharge over side weir at Phase $2\left(\mathrm{~m}^{3} / \mathrm{s}\right)$ :

$Q_{d}=$ downstream water discharge $\left(\mathrm{m}^{3} / \mathrm{s}\right)$;

$Q_{s}=$ spilled water discharge at end of Phase $2\left(\mathrm{~m}^{3} / \mathrm{s}\right)$

$Q_{s}^{0}=$ spilled water discharge at end of Phase $1\left(\mathrm{~m}^{3} / \mathrm{s}\right) ;$

$Q_{u}=$ upstream water discharge $\left(\mathrm{m}^{3} / \mathrm{s}\right)$;

$q_{b s}=$ total unit sediment discharge over side weir at Phase 2 $\left(\mathrm{m}^{2} / \mathrm{s}\right)$;

$T=$ sediment transport parameter $(-)$;

$U=$ mean flow velocity $(\mathrm{m} / \mathrm{s})$; 
$w=$ side weir height at equilibrium phase $2(\mathrm{~m})$;

$z_{b}=$ elevation of main channel bed $(\mathrm{m})$;

$\Delta z=$ bottom step height below side weir at equilibrium phase $2(\mathrm{~m})$;

$\mu=$ discharge coefficient $(-)$;

$\sigma_{g}=$ geometric standard deviation $(-)$; and

$\tau=$ bed-shear stress $\left(\mathrm{N} / \mathrm{m}^{2}\right)$.

\section{References}

Ali, M., Sterk, G., Seeger, M., Boersema, M. P., and Peters, P. (2012). "Effect of hydraulic parameters on sediment transport capacity in overland flow over erodible beds." Hydrol. Earth Syst. Sci., 16(2), 591-601.

Bagnold, R. A. (1966). "An approach to the sediment transport problem from general physics.” U.S. Geological Survey, Washington, DC.

Borghei, S. M., Jalili, M. R., and Ghodsian, M. (1999). "Discharge coefficient for sharp-crested side weirs in subcritical flow." J. Hydraul. Eng., 10.1061/(ASCE)0733-9429(1999)125:10(1051), 1051-1056.

Catella, M., Bechi, G., Paris, E., Rosier, B., and Schleiss, A. J. (2007). "One-dimensional numerical scheme to model bed evolution in presence of a side overflow." Proc., 5th IAHR Symp. on River, Coastal and Estuarine Morphodynamics, CRC Press, London, 1211-1218.

Catella, M., Paris, E., and Solari, L. (2008). "Conservative scheme for numerical modeling of flow in natural geometry." J. Hydraul. Eng., 10.1061/(ASCE)0733-9429(2008)134:6(736), 736-748.

Hager, W. H. (1987). "Lateral outflow over side weirs." J. Hydraul. Eng., 10.1061/(ASCE)0733-9429(1987)113:4(491), 491-504.

Hager, W. H., and Volkart, P. U. (1986). "Distribution channels." J. Hydraul. Eng., 10.1061/(ASCE)0733-9429(1986)112:10(935), 935-952.

Herrero, A., Bateman, A., and Medina, V. (2011). "Experimental analysis of flow and sediment transport in a 90-degrees diversion." Proc., 7th IAHR Symp. on River, Coastal and Estuarine Morphodynamics, Tsinghua University Press, Beijing, 1536-1547.
Hsu, C. C., Tang, C. J., Lee, W. J., and Shieh, M. Y. (2002). "Subcritical 90 equal-width open channel dividing flow." J. Hydraul. Eng., 10.1061/ (ASCE)0733-9429(2002)128:7(716), 716-720.

May, R. W. P., Bromwich, B. C., Gasowski, Y., and Rickard, C. E. (2003). Hydraulic design of side weirs, Thomas Telford, London.

Michelazzo, G., Oumeraci, H., and Paris, E. (2015). "Laboratory study on 3D flow structures induced by zero-height side weir and implications for 1D modeling." J. Hydraul. Eng., 10.1061/(ASCE)HY.1943-7900 $.0001027,04015023$.

Montes, S. (1998). Hydraulics of open channel flow, ASCE, Reston, VA.

Muslu, Y. (2001). "Numerical analysis for lateral weir flow." J. Irrig. Drain. Eng., 10.1061/(ASCE)0733-9437(2001)127:4(246), 246-253.

Nakayama, Y., and Boucher, R. F. (1999). Introduction to fluid mechanics, Butterworth-Heinemann, Oxford.

Neary, V. S., Sotiropoulos, F., and Odgaard, A. J. (1999). "Threedimensional numerical model of lateral-intake inflows." J. Hydraul. Eng., 10.1061/(ASCE)0733-9429(1999)125:2(126), 126-140.

Paris, E., Solari, L., and Bechi, G. (2012). "Applicability of the De Marchi hypothesis for side weir flow in the case of movable beds." J. Hydraul. Eng., 10.1061/(ASCE)HY.1943-7900.0000566, 653-656.

Rosier, B. (2007). "Interaction of side weir overflow with bed-load transport and bed morphology in a channel." Ph.D. thesis, Ecole Polytechnique Fédérale de Lausanne, Lausanne, Switzerland.

Rosier, B., Boillat, J. L., and Schleiss, A. J. (2005). "Influence of side overflow induced local sedimentary deposit on bed form related roughness and intensity of diverted discharge." Proc., 31th IAHR Congress, Seoul.

Rosier, B., Boillat, J. L., and Schleiss, A. J. (2006). "Semi-empirical model to predict mobile bed evolution in presence of a side weir overflow." Proc., 3rd Int. Conf. on Fluvial Hydraulics-River Flow, CRC Press, London, 985-996.

Van Rijn, L. C. (1984). "Sediment transport. I: Bed load transport." J. Hydraul. Eng., 10.1061/(ASCE)0733-9429(1984)110:10(1431), $1431-1456$.

Yang, C. T. (1972). "Unit stream power and sediment transport." J. Hydraul. Div., 98(10), 1805-1826. 